\title{
O uso das terras no sul do Brasil: uma análise a partir de indicadores de localização ${ }^{1}$
}

\author{
Jandir Ferrera de Lima $^{2}$ \\ Lucir Reinaldo Alves ${ }^{3}$ \\ Sandra Mara Pereira ${ }^{4}$ \\ Elvanio Costa de Souza ${ }^{4}$ \\ Paulo Roberto Joner ${ }^{4}$ \\ Adriano de Camargo ${ }^{4}$ \\ Éderson Junior Rodrigues ${ }^{4}$ \\ Pedro Eduardo P. de Andrade ${ }^{4}$
}

\begin{abstract}
RESUMO: Esse artigo analisa o uso das terras no Paraná, Santa Catarina e Rio Grande do Sul, no período de 1975 a 1995, a partir da análise regional. Foram utilizados indicadores de localização e especialização tendo como variável a área em hectares ocupadas nos diversos usos, conforme o Censo Agropecuário. Os resultados apontaram que o padrão espacial do uso das terras na região Sul do Brasil apresenta uma forte reestruturação espacial no Paraná, o uso intensivo das pastagens naturais no Paraná e no Rio Grande do Sul e a maior diversificação no uso terras em Santa Catarina. A análise regional demonstrou uma tendência à redistribuição e reestruturação que ainda não está consolidada.
\end{abstract}

\footnotetext{
${ }^{1}$ Uma versão preliminar deste trabalho fio apresentada no I Congresso Internacional de Desenvolvimento Rural e Agroindústria Familiar em São Luiz Gonzaga (RS), em outubro de 2005.

${ }^{2}$ Ph.D. em desenvolvimento regional pela Université du Québec (UQAC)- Canadá. Professor adjunto do Colegiado de Economia e do Mestrado em Desenvolvimento Regional e Agronegócio na Universidade Estadual do Oeste do Paraná (UNIOESTE)/Campus de Toledo. Pesquisador do Grupo de Estudos e Pesquisas em Agronegócio e Desenvolvimento Regional (GEPEC). Pesquisador Associado do GRIR-UQAC. E-mail: jandir@unioeste.br 3 Mestrando em desenvolvimento regional na Universidade de Santa Cruz do Sul (UNISC). Bel. em Ciências Econômicas pela UNIOESTE/Campus de Toledo. E-mail: lucir_a@hotmail.com

${ }^{4}$ Acadêmica(o) de Ciências Econômicas na UNIOESTE/Campus de Toledo.
} 
Palavras-chave: Desenvolvimento regional, Análise Regional, Localização, Terras.

Classificação JEL: Q15, Q24, R14, R1.

Abstract: This article analyzes the lands uses in the Parana State, Santa Catarina State and Rio Grande do Sul State in Brazil. The regional analysis period is 1975 and 1995. The localization and specialization pointers had been used indicating of having as changeable the area in busy hectares in the diverse uses, as the Farming Census. The results had pointed that the space standard of the lands uses in the Brazilian South region presents strong space reorganization in Paraná State, the intensive use of the natural pastures in the Paraná and the Rio Grande do Sul States and the biggest diversification in the use lands in Santa Catarina State. The regional analysis demonstrated to a trend to the redistribution and reorganization that is still not consolidated.

Key words: Regional development, Regional Analysis, Localization, Lands Uses.

JEL classification: Q15, Q24, R14, R1.

\section{Introdução}

O Sul do Brasil passou por um processo de ocupação espacial que marcou a dinâmica da sua economia, em especial o setor primário. A região Sul teve sua fronteira agrícola definitivamente ocupada em meados da década de 1970. A ocupação das suas terras marcou um intenso processo de atração de população e o aumento da produção agropecuária. Além disso, a ocupação das terras, antes ocupadas somente por florestas nativas, vai estimular sua urbanização de forma acelerada na década de 1980.

Os estudos de SILVA NETO e FRANTZ (2003) confirmam que a ocupação da fronteira agrícola e o processo de urbanização têm paralelo com a forma de exploração e uso das terras. Segundo esses autores, na 
medida em que a ocupação das matas avançava no interior do Sul do Brasil, ocorria uma "metamorfose" no uso das terras e no surgimento de povoados. A dinâmica do povoamento dependia da rentabilidade e dos ganhos de escala das novas atividades extrativas ou agro-pastoris executadas nas áreas ocupadas.

Por outro lado, as possibilidades de ocupação e uso das terras têm, segundo ALMEIDA (2004), efeitos diretos sobre a reestruturação formal do mercado de terras. Sem contar com as diferentes modalidades de apropriação dos recursos naturais. Dessa forma, a ocupação permanente da terra e seu uso caracterizam o "sentido tradicional", ou seja, a forma de diversidade da existência coletiva. O uso da terra demonstra como a existência coletiva mantém sua relação com a natureza, como forma de obter excedentes.

Nesse sentido, coloca-se a seguinte questão: Houve uma mudança no padrão espacial de uso das terras na época da ocupação definitiva da fronteira agrícola e no final do século XX? A resposta para essa questão será útil para os responsáveis pela política fundiária, bem como para o conhecimento das metamorfoses do espaço ocupado. Por isso, essa análise aplica os indicadores de localização e especialização, com o objetivo de traçar o panorama das mudanças no padrão do uso das terras nos Estados do Paraná, Santa Catarina e Rio Grande do Sul. É necessário salientar que a principal limitação desses indicadores é de estabelecer relações de causa e efeito. Eles demonstram as tendências ou regularidades espaciais no movimento de localização dos usos das terras. Assim, os resultados não são necessariamente válidos para o futuro, mas indicarão a situação da localização num determinado período. Portanto, eles serão úteis no planejamento regional, no conhecimento do grau de concentração dos diversos usos das terras nos estados.

\section{Indicadores da análise regional}

Para análise do padrão de localização do uso da terra no Sul do Brasil foram utilizadas medidas de especialização e de localização. Essas medidas proporcionam um quadro de análise do uso das terras nos estados em relação à região Sul do Brasil (PIACENTI E LIMA, 2002 e FERRERA DE LIMA et. al., 2004). 
Além disso, como essas medidas utilizam o peso relativo do uso de terra, elas anulam o efeito "tamanho" dos estados, ou seja, as perturbações introduzidas pelas disparidades de dimensões das regiões. Segundo PUMAIN e SAINT-JULIEN (1997) afirmam que o efeito tamanho gera um coeficiente de correlação sempre elevado e positivo. A solução para evitar o "efeito tamanho" é a comparação de valores relativos e não os valores brutos. Por isso, os indicadores de análise regional são cômodos e confiáveis para o tratamento de variáveis distribuídas em unidades espaciais de tamanhos diferentes. Eles fornecerão uma medida de importância relativa do uso da terra em um estado, comparando o seu "peso" ou participação nos outros estados ou até mesmo no conjunto da região Sul.

Os diferentes usos das terras foram agrupados conforme apresentado no Censo Agropecuário do IBGE (1977, 1996), nos anos 1975 e 1995: Matas e florestas naturais, matas plantadas, lavouras permanentes, lavouras temporárias, lavouras temporárias em descanso, pastagens naturais, pastagens plantadas, terras produtivas não utilizadas e terras inaproveitáveis. Essas informações são organizadas em uma matriz com a distribuição geográfico-espacial da área ocupada em hectares pelos diversos usos. As colunas mostram a distribuição do uso da terra entre os estados, e as linhas mostram a distribuição do uso da terra por modalidade de cada um dos estados, onde $T_{i j}=$ Área usada na modalidade $i$ do estado $j$, conforme Figura 01 .

Figura 01 - Matriz de Informações Geográfico-Espaciais do Uso das Terras

\begin{tabular}{|c|c|c|c|c|}
\hline $\begin{array}{c}\text { Usos da } \\
\text { Terra (ha) }\end{array}$ & \multicolumn{4}{|c|}{} \\
\hline \multirow{4}{*}{$\uparrow$} & & & & \\
\cline { 2 - 5 } & & $T_{i j}$ & & $\sum_{j} T_{i j}$ \\
\cline { 2 - 5 } & & & & \\
\cline { 2 - 5 } & & $\sum_{i} T_{i j}$ & & $\sum_{i} \sum_{j} T_{i j}$ \\
\hline
\end{tabular}

Fonte: Haddad, 1989. 
A partir da matriz de informações, tem-se:

$\sum_{j} T_{i \grave{j}}=$ Área usada na modalidade $i$ de todos os estados;

$\sum_{i} T_{i j}=$ Área usada em todas as modalidades do estado $j$;

$\begin{aligned} & \sum_{i} \sum_{j} T_{i j}= \text { Área usada em todas as modalidades na região Sul do } \\ & \text { Brasil. }\end{aligned}$

Com esse conjunto de somatórios constroem-se as medidas de localização e de especialização. A primeira delas é o quociente de localização ou locacional (QL), que é expresso pela seguinte equação:

$$
Q L_{i j}=\frac{T_{i j} / \sum_{j} T_{i j}}{\sum_{i} T_{i j} / \sum_{i} \sum_{j} T_{i j}}
$$

O Quociente Locacional é utilizado para comparar a participação percentual da área utilizada de um estado com a participação percentual no total da região. O quociente locacional pode ser analisado a partir de modalidades específicas ou no seu conjunto. Quando o $\mathrm{QL}_{\mathrm{ij}} \geq 1$ a proporção de terras empregadas na cultura em uma unidade geográfica específica é maior que a proporção de terras empregadas naquela cultura na unidade geográfica de referência. Além disso, o $\mathrm{QL}_{\mathrm{ij}} \geq 1$ demonstra a importância do estado no contexto regional em relação ao uso estudado, ou seja, o estado é relativamente mais importante em termos do uso em questão, do que em termos gerais de todos os usos.

Na mesma linha do QL, o coeficiente de redistribuição (CRi) relaciona a distribuição percentual do uso da terra em uma mesma modalidade em dois períodos de tempo. Examina se está prevalecendo para a modalidade algum padrão de concentração ou dispersão espacial ao longo do tempo. Os valores próximos a 0 indicam que não terá ocorrido mudanças significativas no padrão espacial de localização da modalidade. Já os valores próximos 01 indicam uma redistribuição significativa. Seu cálculo é expresso pela seguinte equação: 


$$
C R_{i}=\frac{\sum_{j}\left(\left|\frac{T_{i j}^{t 1}}{\sum_{j} T_{i j}}-\frac{T_{i j}^{t 2}}{\sum_{j} T_{i j}}\right|\right)}{2}
$$

O coeficiente de localização (CL) relaciona a distribuição percentual de um uso das terras entre os estados com a distribuição percentual do uso das terras do Sul do Brasil. Seu cálculo é expresso pela equação (03):

$$
C L=\frac{\sum_{j}\left(T_{i j} / \sum_{j} T_{i j}\right)-\left(\sum_{i} T_{i j} / \sum_{i} \sum_{j} T_{i j}\right) \mid}{2}
$$

Se o coeficiente de localização for igual a zero (0), significa que a modalidade de uso i estará distribuída regionalmente da mesma forma que o conjunto de todas as modalidades. Se o valor for igual a um (01), demonstrará que a modalidade i apresenta um padrão de concentração regional mais intenso do que o conjunto de todas as modalidades. Assim, os resultados mais próximos a 0 demonstram uma dispersão significativa no uso das terras. Ao contrário os valores próximos a 01 demonstram uma concentração significativa.

Segundo os estudos de FERRERA DE LIMA (2004), o QL, o CL e o CRi indicam o comportamento do uso das terras no espaço. A utilização desses indicadores permitirá a análise das características de localização a partir de três elementos:

1) O modelo ou a forma de localização num período temporal. Nesse caso, o grau de concentração ou dispersão espacial.

2) O modelo ou a forma das mudanças nas distribuições espaciais nos usos das terras que são produzidos em períodos pré-estabelecidos.

3) O grau de redistribuição espacial ou a estabilidade da localização que caracterizando os usos.

O coeficiente de especialização (CEsp) é uma medida regional. As medidas regionais concentram-se na estrutura do uso da terra de cada estado, fornecendo informações sobre o nível de especialização ou diversificação no uso da terra no período em análise. Através deste coeficiente 
comparam-se as modalidades de uso da terra de um estado com a região Sul. Para resultados iguais a 0 (zero), o estado tem composição idêntica no uso das terras da região Sul. Em contrapartida, coeficientes iguais ou próximos a 01 demonstram um elevado grau de especialização ligado a um determinado uso, ou seja, está com uma estrutura de utilização das terras totalmente diversa do conjunto da região Sul.

$$
\operatorname{CEsp}_{j}=\frac{\sum_{i}\left|\left(T_{i j} / \sum_{i} T_{i j}\right)-\left(\sum_{j} T_{i j} / \sum_{i} \sum_{j} T_{i j}\right)\right|}{2}
$$

O coeficiente de reestruturação (Cr), apresentado na equação (05), relaciona a estrutura do uso da terra na região entre dois períodos, ano base 0 e ano 01, objetivando verificar o grau de mudanças na modalidade de uso dos estados que compõem cada região. Coeficientes iguais a zero (0) indicam que não ocorreram modificações na estrutura do uso das terras do estado, e iguais a um (01) demonstra uma reestruturação bem substancial.

$$
C r=\frac{\sum_{i}\left|\left(T_{i j} / \sum_{i} T_{i j}\right)-\left(T_{i j} / \sum_{i} T_{i j}\right)\right|}{2}
$$

No caso dos coeficientes de especialização e reestruturação, eles consideram cada estado individualmente apresentando suas características e seu comportamento. Nesse caso, eles consideram os efeitos regionais das tendências e dos tipos de localização. No caso do Coeficiente de Reestruturação, ele fornecerá elementos sobre a estrutura de ocupação do espaço rural, no caso o grau de reestruturação ou a estabilidade estrutural para os períodos em análise. 


\section{O Peso Locacional do Uso das Terras}

A Figura 02 apresenta peculiaridades com relação à localização dos usos das terras. No Paraná, as lavouras temporárias em descanso apresentaram uma evolução no seu perfil locacional. Essa modalidade de uso aos poucos vai ganhando mais representatividade, ou seja, a proporção de terras empregadas nessas culturas vem aumentando nas unidades geográficas. Com exceção das lavouras temporárias e pastagens naturais, cujo padrão de localização continua estável, os outros usos tiveram redução no Quociente de Localização. As reduções mais significativas foram das lavouras permanentes, das terras produtivas não utilizadas e das terras inaproveitáveis. Assim, no caso paranaense, o espaço agrário vem otimizando o uso das áreas utilizáveis. A ocupação do espaço rural, antes extensiva, vem ficando cada vez mais intensiva. PADILHA JUNIOR e BERGER (2005) confirmam esse fato. Segundo seus estudos, os produtos agrícolas paranaenses apresentaram uma expansão média de área plantada de $24,4 \%$, além de um incremento médio de $20,6 \%$ na produtividade e $50 \%$ na produção agrícola. Assim, a rentabilidade gerada pelos produtos agrícolas no Paraná pode estimular o rumo dos usos destinados a outras atividades, em especial das áreas de florestas naturais ou reflorestamentos. Tanto que o padrão de localização das matas naturais e plantadas diminuiu entre 1975 e 1995 (Anexo I).

Além dos dados do Anexo I, que confirmam essa afirmação, OLIVEIRA e BACHA (2003) demonstram a redução significativa da percentagem de imóveis rurais nos estados da região Sul que registram a presença de reserva legal. Em Santa Catarina, por exemplo, houve uma redução de 8,01\% em 1972 para 3,20\% em 1998. No Rio Grande do Sul a redução foi de $14,46 \%$ para 3,31\% no mesmo período. O Paraná tem indicadores estáveis com 6,77\% em 1972 para 7,67\% em 1998. 
Figura 02 - Quociente Locacional (QL) do Uso das Terras no Sul do Brasil (1975/1995)

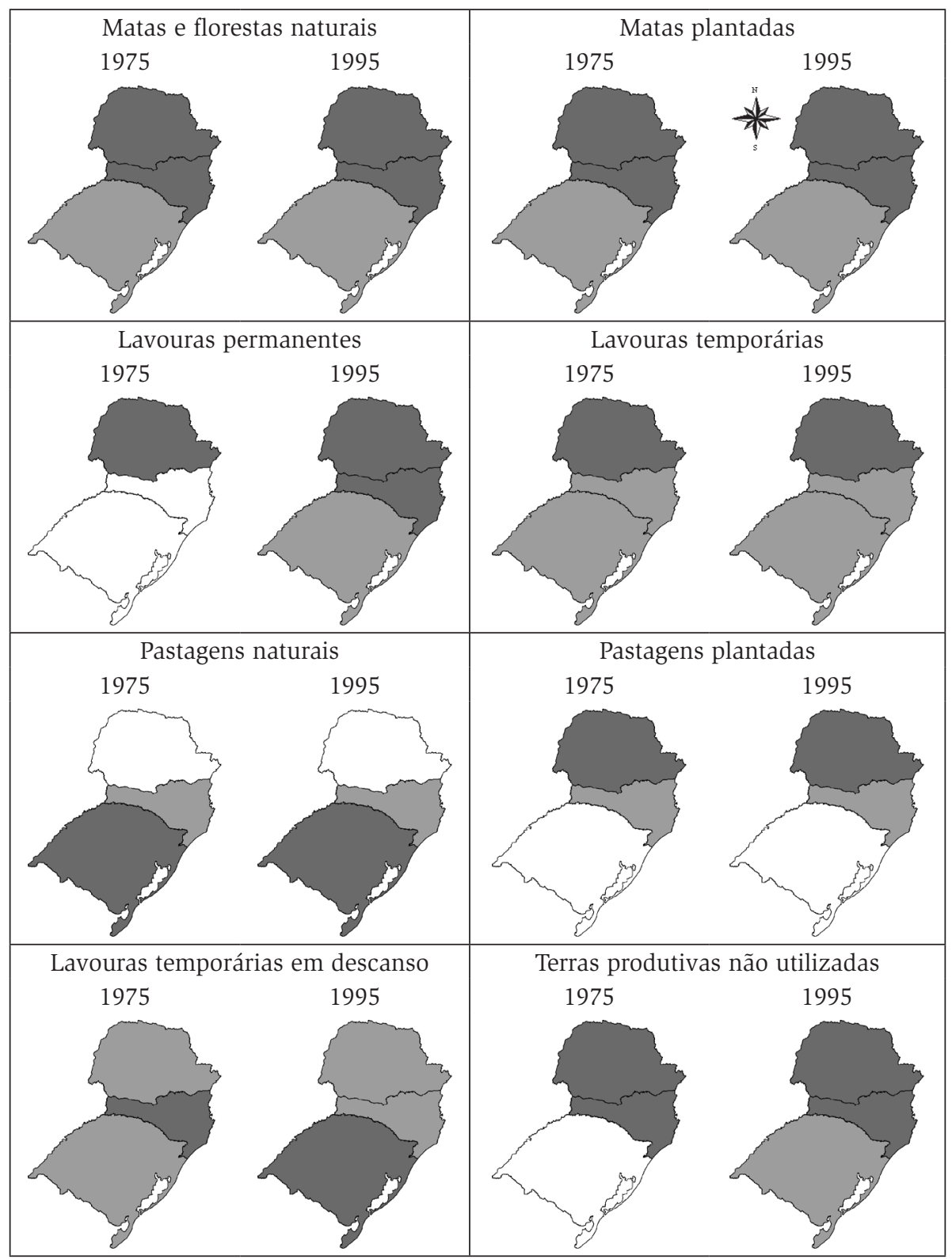




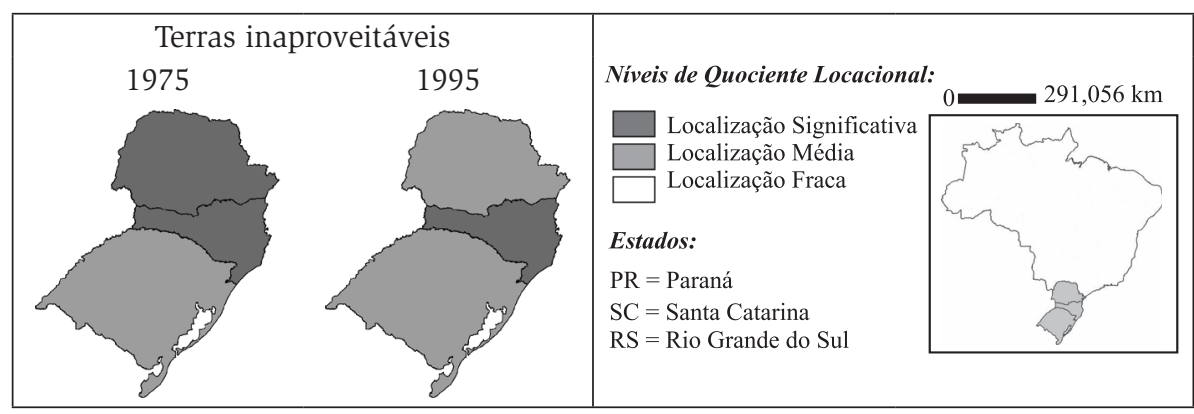

Fonte: Resultados da Pesquisa (Anexo I).

Diferente do Paraná, no Rio Grande do Sul as pastagens naturais tem uma localização predominante. Como uma boa parte do território gaúcho está no ecossistema da Pampa, cujas pastagens naturais são de alta qualidade para a pecuária extensiva, isso explica essa tendência ao uso da terra. Outro fato que marca o RS é a expansão do padrão de localização das lavouras permanentes e das terras produtivas não utilizadas. De uma localização pouco expressiva, o indicador desses usos evoluiu para um Quociente de Localização médio. Enquanto isso, as lavouras temporárias em descanso avançaram e ganharam um padrão de localização no período de análise. Isso demonstra que as culturas sazonais têm ganhado um espaço mais significativo ao longo desses anos.

Em Santa Catarina, as matas plantadas e as terras inaproveitáveis reforçaram sua localização. As matas plantadas, em função dos programas de reflorestamento, e as terras inaproveitáveis por causa das condições do relevo catarinense, com suas ondulações e uma geografia acidentada. Por outro lado, as lavouras permanentes ganharam mais terreno no espaço agriculturável, substituindo as pastagens plantadas e as lavouras temporárias em descanso. Assim, em Santa Catarina, as terras utilizadas na pecuária vêm sendo substituídas pela agricultura. Esse fato é evidenciado também no contexto geral da utilização das terras na região Sul, conforme Gráfico 01, onde as pastagens naturais e plantadas apresentam a maior proporção de terras utilizadas. No caso, as pastagens naturais no Rio Grande do Sul e as plantadas no Paraná.

Deve-se salientar que IGREJA e BLISKA (2004) relacionam o remanejamento do uso das áreas agrícolas com o perfil das cadeias produtivas. Nesse caso, o avanço das pastagens cultivadas sobre outros usos da terra 
é o resultado do avanço das pecuárias de corte e leiteira, mais significativas nos estabelecimentos médios. Os autores ainda salientam que no Rio Grande do Sul as pastagens naturais fazem parte de um manejo adequado e integrado à rotação de culturas.

Por outro lado, as lavouras temporárias e as terras inaproveitáveis vêm intensificando seu padrão de concentração regional no conjunto dos usos das terras. Assim, no contexto da região Sul, os indicadores demonstram uma tendência à expansão das lavouras temporárias e das pastagens plantadas.

Gráfico 01 - Coeficiente de Localização (CL) da utilização das Terras da Região Sul do Brasil - 1975 e 1995

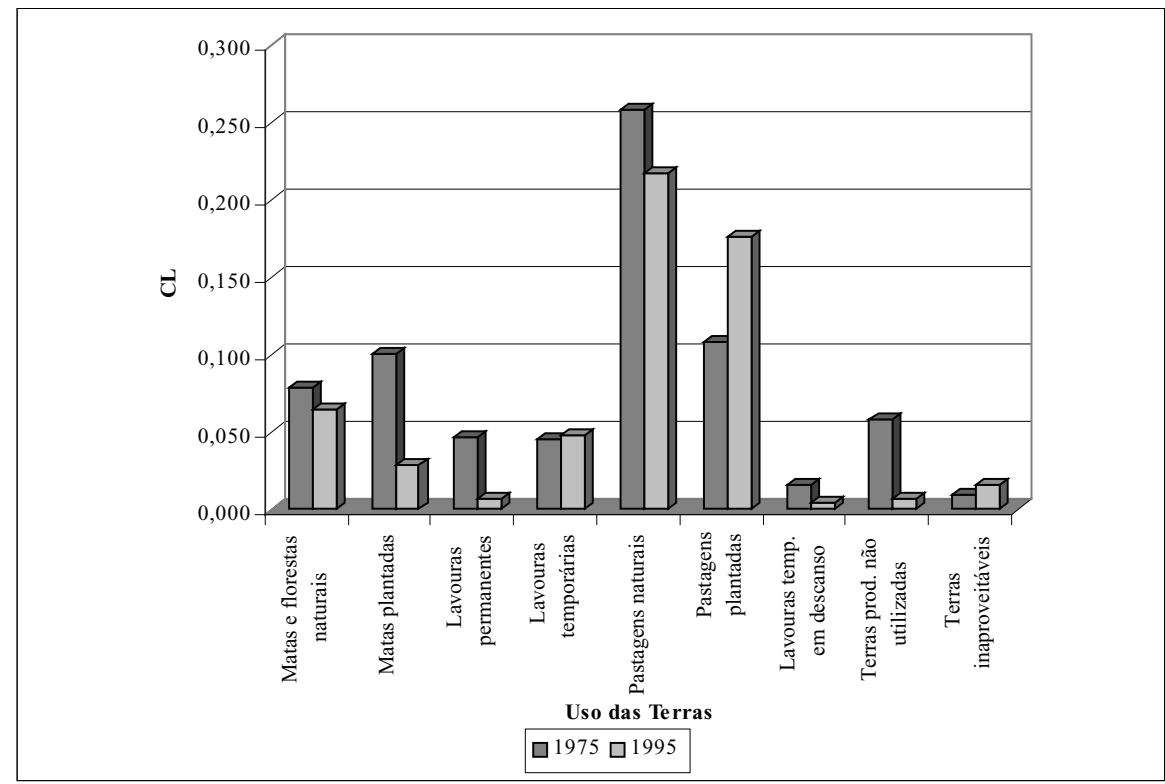

Fonte: Resultados da Pesquisa.

No caso do Rio Grande do Sul, que possui a extensão mais significativa de pastagens naturais, a expansão dos arrozais, das lavouras de soja e até mesmo da desertificação na sua fronteira Oeste são fatores que explicam uma mudança no perfil de localização das pastagens e o avanço das lavouras e das terras inaproveitáveis no Sul do Brasil. O estudo de IGREJA 
e BLISKA (2004) salienta que outros fatores impactam no uso dos solos, em especial na concentração espacial desses usos, quais sejam: o mercado de terras, barreiras ao aumento das áreas plantadas e as restrições legais e ambientais. Esses elementos reforçam a mutação nos usos das terras determinando a alocação de diferentes culturas ou deixando os solos sem condições de produção. Como o Coeficiente de Localização não aponta a causa do fenômeno, mas uma "fotografia instantânea" do mesmo, então se exige pesquisas mais detalhadas sobre os diversos fatores que vêm impactando na mudança do perfil locacional das diferentes formas de utilização das terras. No caso dessa análise, os resultados demonstram que a maioria dos usos está distribuída de forma eqüitativa, segundo a distribuição espacial dos usos nos diferentes estados. A exceção fica por conta das pastagens plantadas e das lavouras temporárias. No caso das pastagens, a paisagem dos estados sulinos, caracterizados pelos campos gerais, os campos de cima da serra e a pampa, são estímulos à pecuária e com isso à manutenção desses ecossistemas. No caso das lavouras, a soja, o algodão, o milho e as culturas de inverno (aveia, trigo) são também marcantes na agricultura regional.

\section{Redistribuição e Reestruturação do Uso das Terras.}

No período de análise, o padrão espacial de redistribuição do uso das terras foi significativo para as terras produtivas inutilizadas, as pastagens plantadas e as pastagens naturais (Gráfico 02). Esses usos apresentaram uma redistribuição mais significativa, ou seja, as alterações na ocupação das áreas de terra com esses modos de exploração foram os mais importantes no contexto regional. Os outros usos, apesar das mudanças no padrão de uso em um estado em particular, não tiveram alterações regionais significativas.

Comparando o Gráfico 02 com as informações da Figura 02 e do Gráfico 01 nota-se que a redistribuição ocorrida no uso das terras para pastagens fortaleceu o padrão de localização das lavouras permanentes. A redistribuição das terras demonstra, pouco a pouco, uma substituição da pecuária em detrimento da agricultura. Confrontando esses dados com o Coeficiente de Localização, seria conveniente afirmar que a longo prazo as lavouras temporárias adentrarão no espaço antes destinado à 
pecuária, como os campos gerais, os campos de cima da serra, a pampa e talvez o planalto médio do Sul do Brasil. Essa substituição está ocorrendo lentamente e outros estudos ao longo do século XXI poderão confirmar essa tendência. Em todo caso, esse dado confirma um estudo feito por IGREJA, CAMPOS e BLISKA (2001), que comprovou uma propensão maior para a concentração das pastagens naturais no Sul do Brasil. Segundo esse estudo, os aumentos e diminuições das pastagens refletem as oscilações nas economias de escala.

Gráfico 02 - Coeficiente de Redistribuição do Uso das Terras no Sul do Brasil (1975-1995)

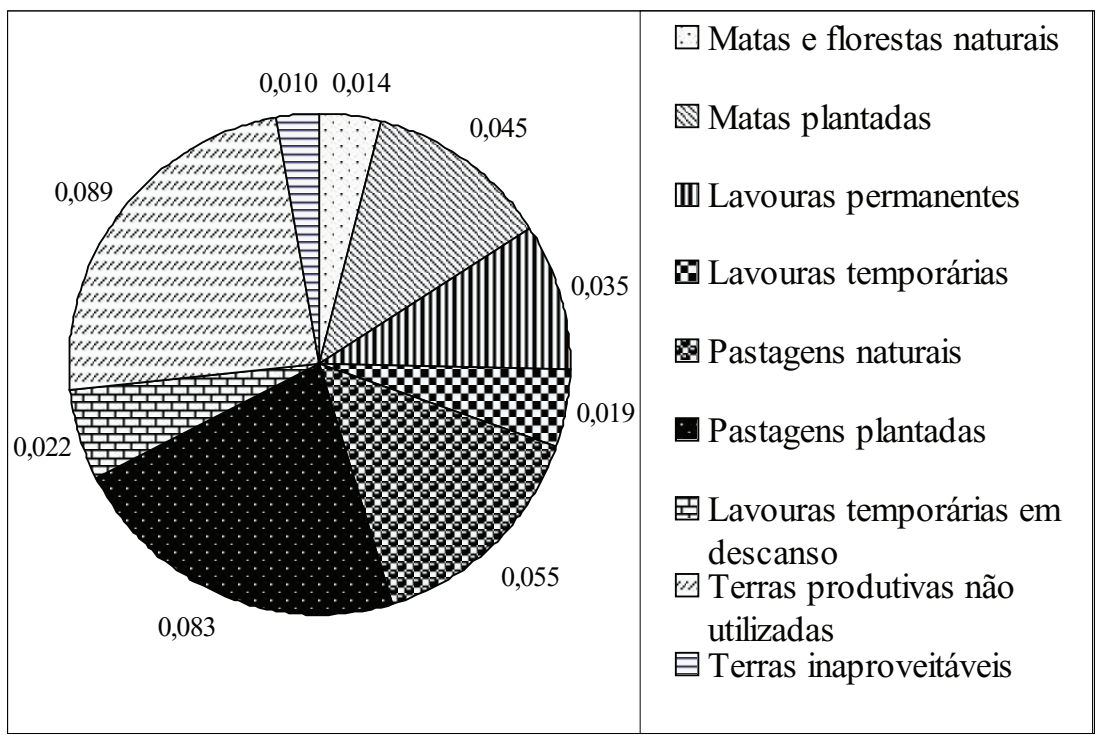

Fonte: Resultados da Pesquisa.

Da mesma maneira, as terras inaproveitáveis, em função das condições de relevo ou pelo seu esgotamento, também vêm se mostrando relevantes. Essa redistribuição acarretou reestruturações bem particulares na região Sul. Pelo Gráfico 03 nota-se que o Paraná apresentou a maior reestruturação espacial no uso das terras entre 1975-1995, seguido do Rio Grande do Sul e Santa Catarina. Esse dado reflete a dinâmica da agropecuária paranaense, em duas frentes: a primeira, o fato que o Paraná foi o último estado a ter sua fronteira agrícola ocupada; a se- 
gunda, a diversificação dos usos da terra. Ao comparar-se o Gráfico 03 com a Figura 02, é possível notar que os usos no Paraná vêm mudando o padrão locacional, reforçando os indicadores que eram mais fracos e diminuindo a intensidade dos indicadores que eram os mais significativos em 1975.

Segundo IGREJA, CAMPOS e BLISKA (2001) e IGREJA e BLISKA (2004) o Paraná tem auferido economias de escala na pecuária e um padrão de produtividade acentuado nas lavouras temporárias e permanentes, estimulando retornos maiores e o uso cada vez mais intensivo dos solos, fato confirmado pelos Gráficos 03 e 04 .

Gráfico 03 - Coeficiente de Reestruturação (CRe) do Uso das Terras no Sul do Brasil (1975-1995)

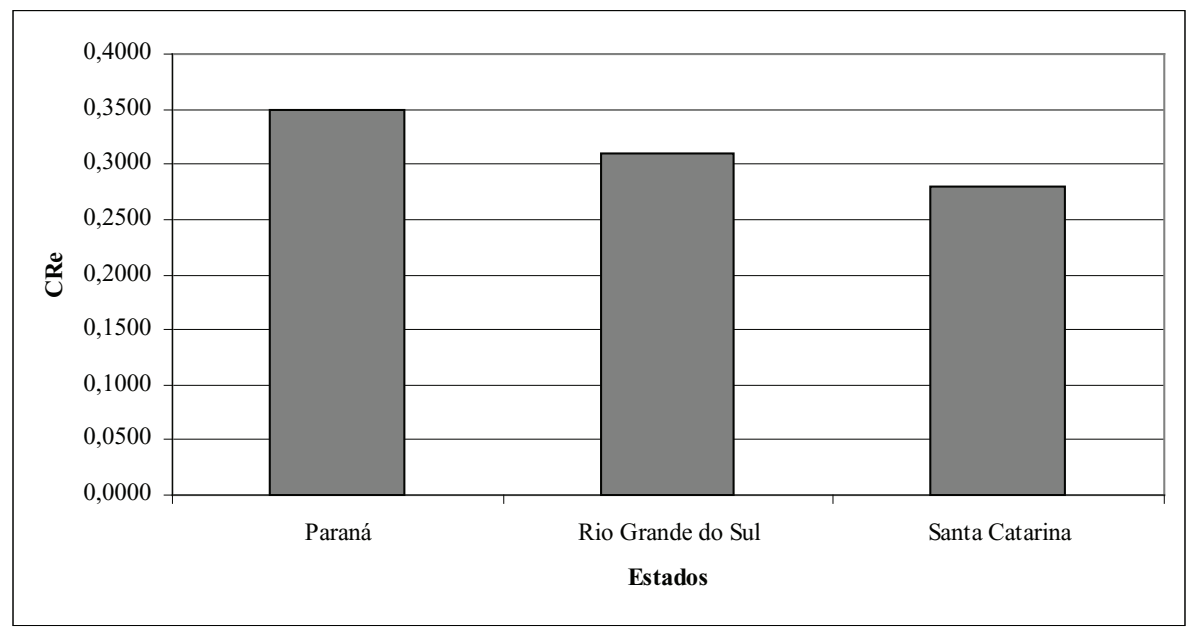

Fonte: Resultados da Pesquisa.

A reestruturação no uso das terras fez com que o Sul do Brasil convergisse numa maior diversificação dos usos, conforme Gráfico 04.

De acordo com o Gráfico 04 o Estado do Paraná foi o que mais diversificou-se no período de 1975 a 1995. No entanto, é o Estado de Santa Catarina que apresenta o melhor coeficiente, ou seja, é o estado com maior diversificação de uso da terra na região Sul. Ao contrário, o Rio Grande do Sul demonstrou uma especialização maior no mesmo período. 
Gráfico 04 - Coeficiente de Especialização (CEsp) do Uso das Terras no Sul do Brasil - 1975/1995

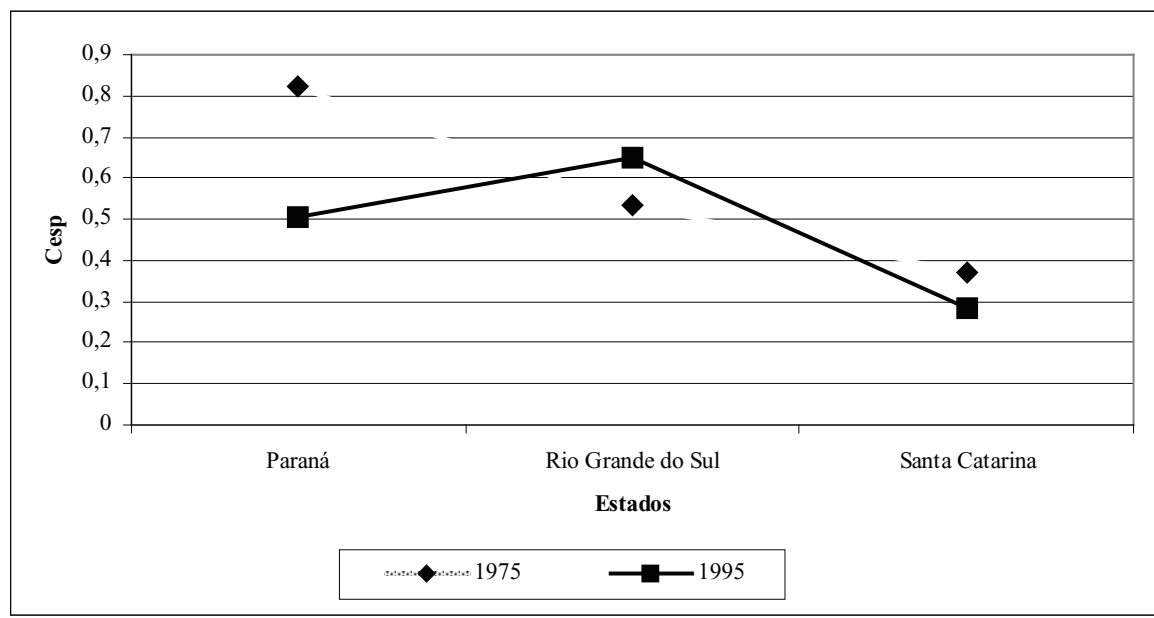

Fonte: Resultados da Pesquisa.

\section{Conclusão}

O objetivo desse artigo foi analisar o padrão de localização do uso das terras nos estados da região Sul do Brasil, nos anos de 1975 e 1995, a partir de indicadores de localização e especialização.

O padrão espacial do uso das terras no Sul do Brasil, entre 1975 e 1995, apresenta peculiaridades, sendo elas:

A primeira é o perfil de reestruturação espacial, onde o indicador do Paraná é destaque. No caso, o Paraná foi o ultimo Estado do Sul a ter uma fronteira agrícola ocupada, sem contar nas poucas restrições ao aumento das áreas plantadas até 1995.

A segunda é o papel desempenhado pelas pastagens no Rio Grande do Sul e Paraná. Apesar das pastagens naturais terem um peso significativo na localização, dada a geografia da Pampa gaúcha, o aumento das pastagens naturais no Paraná reflete ganhos de escala e o avanço técnico das pecuárias de corte e leiteira.

A terceira é o padrão locacional de Santa Catarina. Esse estado é o mais diversificado no uso dos solos. Por outro lado, suas características geográficas marcam-lhe com a localização mais significativa de terras 
produtivas não utilizadas, terras inaproveitáveis, florestas e lavouras permanentes.

Assim, como se observou pela análise, os diferentes usos estão bem distribuídos no Sul do Brasil. Os outros comparativos incluindo os próximos censos agropecuários poderão traçar a tendência definitiva do uso das terras. Até porque, a análise regional demonstrou uma tendência à redistribuição e reestruturação que não está consolidada.

\section{Referências Bibliográficas}

ALMEIDA, Alfredo Wagner. Terras tradicionalmente ocupadas. Revista Brasileira de Estudos Regionais. Rio de Janeiro, vol. 06, no. 01, p.0931, 2004.

FERRERA DE LIMA, J. La diffusion spatiale du développement économique régional:L'analyse des composantes et de la forme de la diffusion spatiale au Sud du Brésil au $\mathrm{XX}^{\mathrm{e}}$ siècle. Thèse de doctorat en développement régional, DSH/Université du Québec à Chicoutimi, Saguenay. Disponível on-line no site Web http://www.irec.net/01fr_rechercheaffiche.php3?518, 2004.

FERRERA DE LIMA, J.; PIACENTI, C. A.; ALVES, L. R. e PIFFER, M. A localização e as mudanças da distribuição setorial do PIB nos estados da região Sul (1970-1998). IN: CONGRESSO BRASILEIRO DE ECONOMIA E SOCIOLOGIA RURAL (SOBER), Cuiabá, Anais... Cuiabá: SOBER, 2004. 1 CD-ROM.

HADDAD, J. H. (Org.). Economia regional: teoria e métodos de análise. Fortaleza. BNB/ETIENE, 1989.

IGREJA, A.; BLISKA, F. Análise econômica dos efeitos de substituição de pastagens cultivadas nos estados de São Paulo e da região Sul do Brasil. Teoria e Evidência Econômica, Passo Fundo, v. 12, n. 23, p. 09-24, nov. 2004.

IGREJA, A.; CAMPOS, B.; BLISKA, F. Estudo dos impactos locativos das pastagens na região Centro-Sul do Brasil. Agricultura em São Paulo, São Paulo, v. 48, n. 1, p. 119-140, 2001. 
INSTITUTO BRASILEIRO DE GEOGRAFIA E ESTATÍSTICA (IBGE). Censo Agropecuário de 1975. Rio de Janeiro: IBGE, 1977.

INSTITUTO BRASILEIRO DE GEOGRAFIA E ESTATÍSTICA (IBGE). Censo Agropecuário de 1995. Rio de Janeiro: IBGE, 1996.

OLIVEIRA, S. J. M.; BACHA, C. J. C. Avaliação do cumprimento da reserva legal no Brasil. Revista de Economia e Agronegócio, v. 1, n. 2, abr./jun. 2003.

PADILHA JUNIOR, J. B.; BERGER, R. O impacto da reserva legal florestal sobre a agropecuária paranaense, em um ambiente de risco. Revista da FAE, Curitiba, v. 8, n. 1, p. 51-68, jan./jun. 2005

PIACENTI, C. A.; LIMA, J. F. (Coord.). Análise do impacto dos reservatórios das hidroelétricas no desenvolvimento econômico microrregional. Toledo: UNIOESTE/Campus de Toledo, março/2001. 245 p. (Relatório de Pesquisa. UNIOESTE - Campus de Toledo/Fundação Araucária - Projeto 612.) projeto concluído. 2002.

PIACENTI, C. A.; LIMA, J. F.; ALVES, L. R.; PIFFER, M.; STAMM, C. Análise regional dos municípios lindeiros ao lago da Usina Hidroelétrica de Itaipu. In: ENCONTRO BRASILEIRO DE ESTUDOS REGIONAIS E URBANOS, 2, 2002, São Paulo, Anais... São Paulo: ABER, 2002. 1 CD-ROM.

PUMAIN, D; SAINT-JULIEN, T. L’analyse spatiale: localizations dans l'espace. Paris: Armand Colin, 1997.

SILVA NETO, B.; FRANTZ, T. R. Dinâmica da agricultura e desenvolvimento no Rio Grande do Sul. Revista de Economia e Sociologia Rural, v. 41, n. 3, jul./set. 2003 . 


\section{Anexo I}

Quociente de Localização (QL) do Uso das Terras no Sul do Brasil $(1975 / 1995)$

\begin{tabular}{l|c|c|c|c|cc}
\hline \multirow{2}{*}{\multicolumn{1}{c}{ Usos das Terras }} & \multicolumn{2}{c|}{ Paraná } & \multicolumn{2}{c|}{$\begin{array}{c}\text { Rio Grande } \\
\text { do Sul }\end{array}$} & \multicolumn{2}{c}{ Santa Catarina } \\
\cline { 2 - 8 } & 1975 & 1995 & 1975 & 1995 & 1975 & 1995 \\
\hline Matas e florestas naturais & 1,16 & 1,09 & 0,63 & 0,72 & 1,93 & 1,70 \\
Matas plantadas & 1,27 & 1,04 & 0,73 & 0,67 & 1,38 & 1,98 \\
Lavouras permanentes & 2,50 & 1,34 & 0,25 & 0,66 & 0,20 & 1,31 \\
Lavouras temporárias & 1,13 & 1,14 & 0,97 & 0,95 & 0,81 & 0,83 \\
Pastagens naturais & 0,30 & 0,27 & 1,52 & 1,57 & 0,79 & 0,87 \\
Pastagens plantadas & 2,20 & 2,10 & 0,31 & 0,33 & 0,65 & 0,53 \\
Lavouras temporárias em descanso & 0,79 & 0,91 & 0,77 & 1,10 & 2,28 & 0,88 \\
Terras produtivas não utilizadas & 1,71 & 1,17 & 0,38 & 0,72 & 1,57 & 1,51 \\
Terras inaproveitáveis & 1,00 & 0,86 & 0,92 & 0,97 & 1,28 & 1,43 \\
\hline
\end{tabular}

Fonte: Resultados da Pesquisa.

Recebido em fevereiro de 2006 e revisto em junho de 2006. 